\title{
LIGHT AND TRANSMISSION ELECTRON MICROSCOPICAL CHANGES ASSOCIATED WITH GASTRITIS IN TIGER (PANTHERA TIGRIS)
}

\author{
OMAR, A.S TAMAM
}

Department of Natural Resources., Environmental studies and Research Institute, University of Sadat city, Sadat city, Egypt. E-mail: Otamam2002@hotmail.com

\section{ABSTRACT}

Received at: 14/11/2013

Three dead tigers were dissected and representative samples from the gastric mucosa, duodenum and livers were taken for histopathology and transmission electron microscope for further investigation of the cause of death. Post-mortum examination showed accumulation of straw in the stomach outlet (Phytobezoar), together with pronounced ulcers, which was surrounded by hemorrhagic zones.

Accepted: 22/1/2014 Light microscopy showed loss of the gastric mucosal epithelium, necrosis of the gastric glands, hyperemia of the submucosal blood vessels, and lymphocytic and few neutrophils in the submucosa. These changes indicated acute-subacute gastritis. Subcapsular hepatocellular necrosis expressed by hepatocellular lysis, pyknosis and karyorhexis of the hepatocytes nuclei were also observed. Transmission electron microscopical observations showed the presence of intercellular, and interacellular elongated, coiled, and spiral form of Hellicobacter bacteria in close contact with the gastric glandular epithelium. Moreover, rounded-shaped bacteria were observed in association with the helicobacter bacteria. The duodenum revealed also the presence of both types of bacteria. These results suggest mixed infection with the complication of Phytobezoar which cause obliteration of the stomach outlet with chronic constipation and fever, might be responsible for the death of tiger.

Key Words: Tiger, Helicobacter bacteria, gastritis, Phytobezoar

\section{INTRODUCTION}

The tiger (Panthera tigris) is the world's largest cat and is one of the most threatened with extinction. As recently as 100 years ago, there were as many as 100,000 wild tigers living in Asia. Today, fewer than 3,200 remain. Tigers are currently listed as "Endangered" on the International Union of the Conservation of Nature's (IUCN) Red List of Threatened Species (IUCN 2012). Death of tigers in captivity usually related to either fighting or senility but the infectious and non-infectious diseases now become under complete control (personal communication). Phytobezoar is a concretion formed in the stomach or intestine and composed chiefly of undigested compacted vegetable fiber, usually it cure spontaneously by vomiting but in rare case it complicated even to Emphysematous gastritis with perforation of the stomach (Lagios and Suydam 1968). Straw Phytobezoar create a fatal disease in the tigers and lions as obliterate the stomach so complicated to Emphysematous gastritis, gastric ulcers, constipation, fever and death (personal communication). Nausea, vomiting, gastric outlet obstruction, perforation, abdominal pain, and bleeding have been reported in the stomachs of slaughtered plant-eating animals (Chisholm et al., 1992).

\section{MATERIALS and METHODS}

Three Bengal tiger (panther tigris) showed dead between May 2009 and March 2012. Two cases in the Egyptian cercus and the last one in the Alexandria private zoo, all revealed symptoms of Nausea, vomiting, fever $>38.8^{\circ} \mathrm{C}$ (normal temperature $37.5^{\circ} \mathrm{C}$ or $99.5^{\circ} \mathrm{F}$ ), off food, lethargy, not response to the treatment by antibiotics, antiemetic and stimulant drugs. These animals underwent a thorough postmortem examinations, Tissues with lesions were removed and fixed in $10 \%$ buffered formalin, serial concentrations of alcohol followed by xylene then paraffin-wax embedded for histological examination. $3 \mu \mathrm{m}$-thick sections were mounted on slides and stained with haematoxylin-eosin for a general histological view. Direct smear from the gastric and intestinal mucosa take and studied for parasites. In addition advantage examination performed on the last tiger as tissue sections were perfuse using the modified Karnovsky solution, containing 2.5\% glutaraldehyde, $2 \%$ paraformaldehyde in a $0.1 \mathrm{M}(\mathrm{pH}$ 7.3 ) containing $2.5 \%$. sodium cacodilate buffer. Then, the tissues were fixed in the same solution for 12 hours at $4{ }^{\circ} \mathrm{C}$. The phantom of the operate specimens were post fixed in $2 \%$ osmium tetroxide solution, rinsed in distilled water, and immersed in $2 \%$ tannic acid solution for 1 hour at room temperature (Murakami, 1974). Then, the tissues were dehydrated 
in an increasing series of ethanol and propylene oxide and embedded in Spurr resin. The thick sections were made in Porter Blum ultra microtome using glass knives and stained with toluidin blue solution for light microscopy analysis. For thin sections were used ultra microtome Ultra-Cut Reichert with diamond knife. The ultrathin sections were mounted on 200 and 300 mesh grids, counterstained with uranyl acetate and lead citrate and examined in transmission electron microscopy Joel, JSM1010at $100 \mathrm{kV}$.

\section{RESULTS}

Accumulation of straw in the stomach of dead tiger was observed in the form of ball-like structure (Phytobezoar) during postmortem examination (Fig.1c). Moreover, pronounced circumscribed ulcers were observed and surrounded by hemorrhagic zone (Fig.1d).

\section{Light microscopy:}

\section{A. Stomach:}

Histopathological examination of the tiger stomach showed ulcers of its mucosa, which was expressed by loss of the surface epi8thelium of the mucosa as well as degenerative and necrotic changes of the gastric glands (Figs. 2;3). Fig.4 showed hyperemia of the submucosal blood vessels, which was expressed by dilation and engorgement with blood. Within the hyperemic blood vessels several vacuoles were observed in close contact with the endothelium of tunica intima (Fig.5). Pronounced inflammatory cellular reaction mainly of lymphocytes and neutrophils were also observed in the submucosa (Fig.6).

\section{B. Liver:}

Sub-capsular hepatocellular necrosis was observed (Fig.7).This necrotic area was expressed by hepatocellular lysis, pyknosis, and karyorehexis of nuclei (Figs. 8;9).

\section{Transmission Electron microscope:}

\section{A. Stomach:}

Abundant electron dense structures in close contact with the gastric glandular epithelium was noticed (Fig.10).These structures were elongated, helical-like or spiral shape belong to Helicobacter spp.(Fig.11). These bacteria were also observed between the gastric glands near the gastric pet (Fig. 12). In addition to the spiral helicobacter bacteria, rounded-shaped electron dense bacteria were also observed between the gastric glands (Fig.13). Intracellular localization of the bacteria was observed in close contact to the mitochondria (Fig.14).

\section{B. duodenum:}

Figs. $15 ; 16$ showed intracellular localization of the electron-dense rounded bacteria surrounded by a halo and inside phagolysosomes. A coiled spiral helicobacter bacteria and the rounded electron-dense bacteria were also observed intracellular (Fig.17).

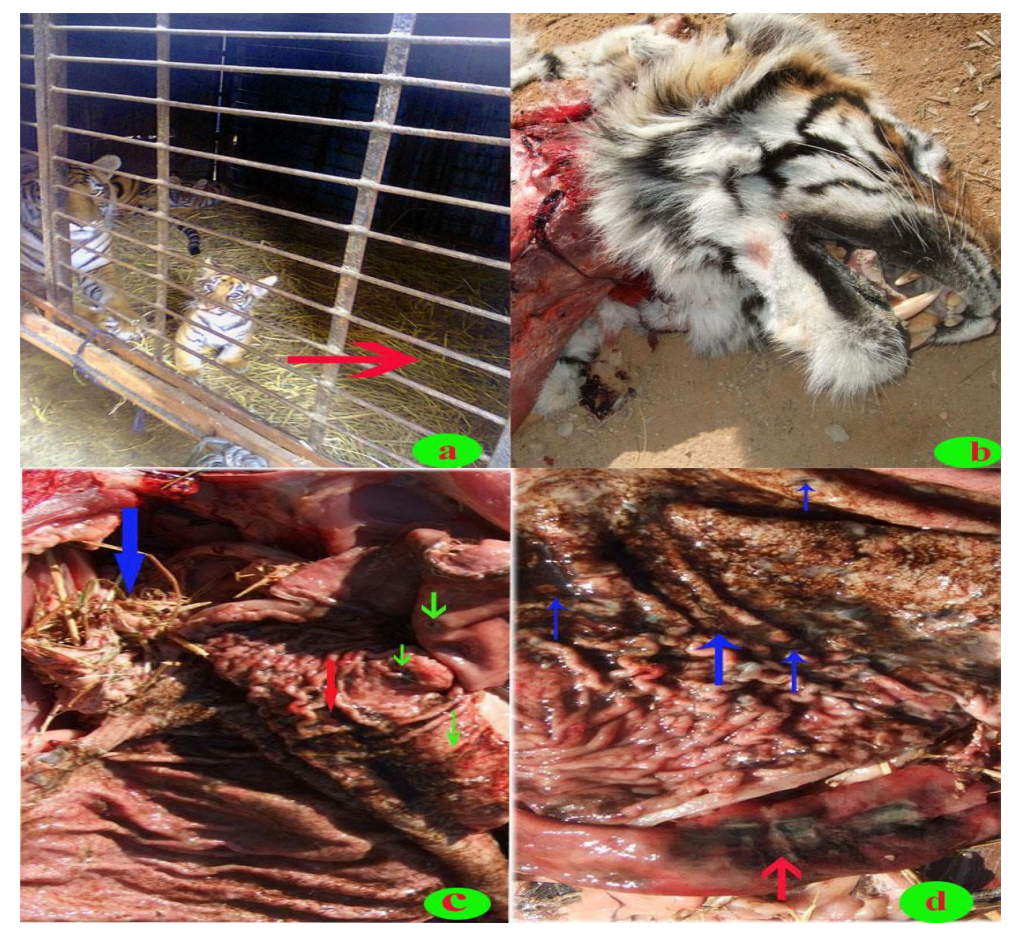

Fig.1: A tigress with her cubs on straw (a). Adult Dead Tiger during PM showing the complete dentation (b). Stomach had accumulation of straw (Thick arrow) and few ulcers (small arrows) (c). Pronounced circumscribed ulcers surrounded by hemorrhagic zone (Bottom arrow) with duodenal necrosis (red arrow) (d). 


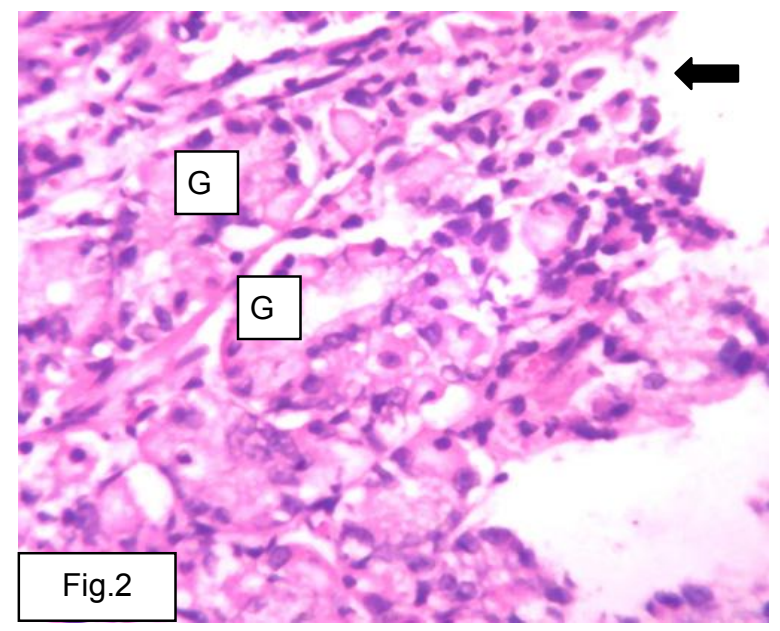

Fig.2: Tiger stomach showing loss of surface epithelium of the mucosa (arrow) and degeneration of gastric glands (G).X40.

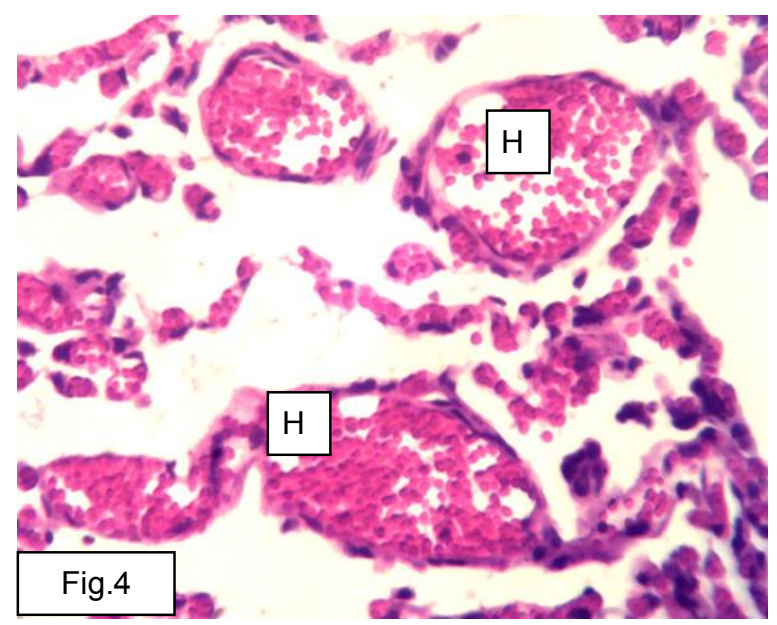

Fig.4: Tiger stomach showing hyperemia of submucosal H\&E. X40.

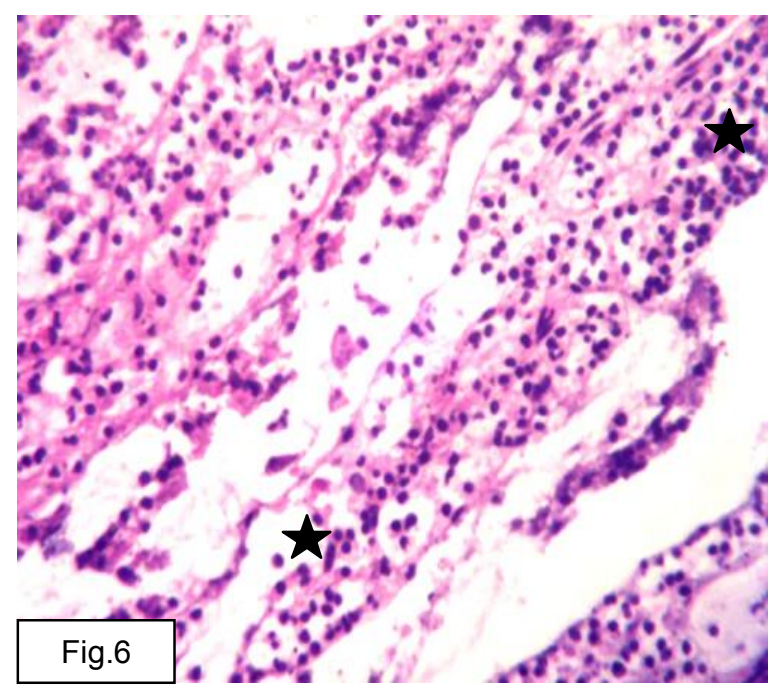

Fig.6: Tiger stomach showing inflammatory cellular reaction. $(*)$. H\&E.X10

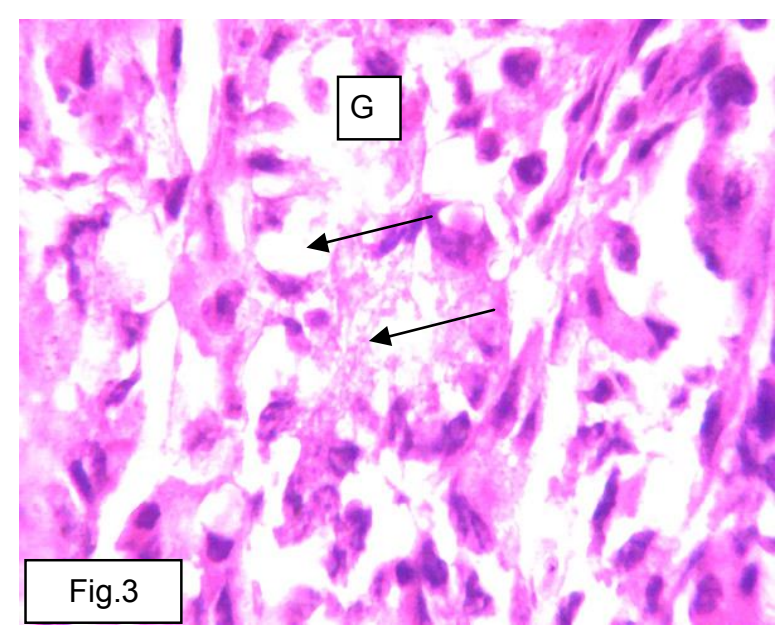

Fig.3: Higher magnification of Fig.2 showing necrosis of gastric glands (arrow). H\&E. X40.

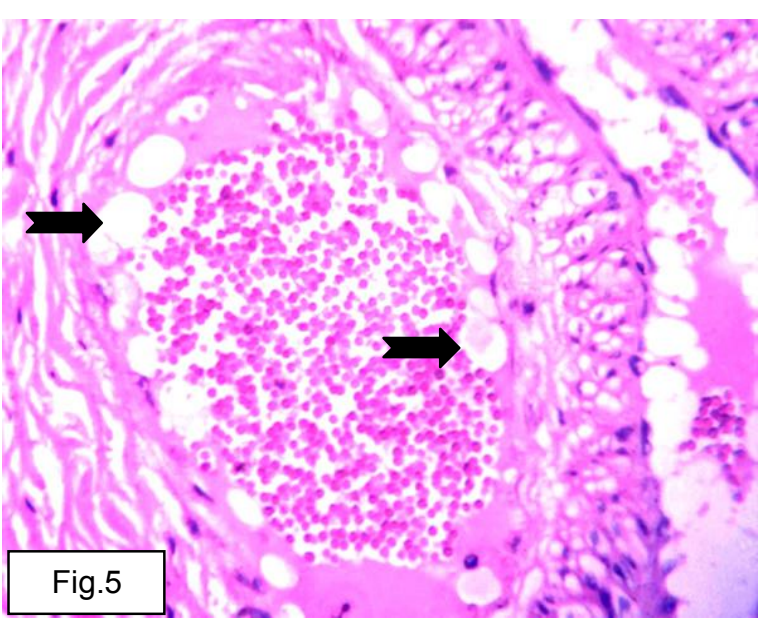

Fig.5: Tiger stomach showing hyperemic blood vessel with accumulation of several vacuoles (head arrow). X40

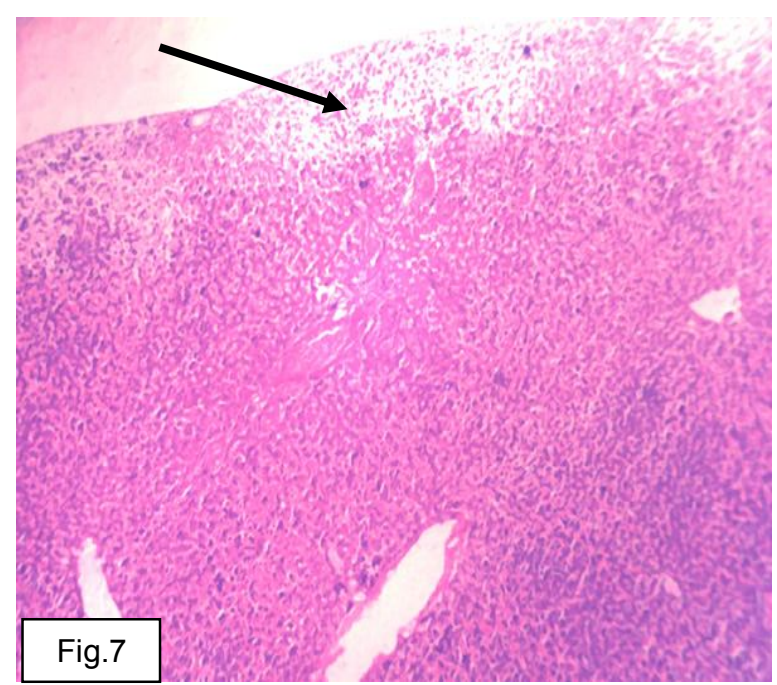

Fig7: Tiger liver showing subcapscular necrosis (arrow).X10 


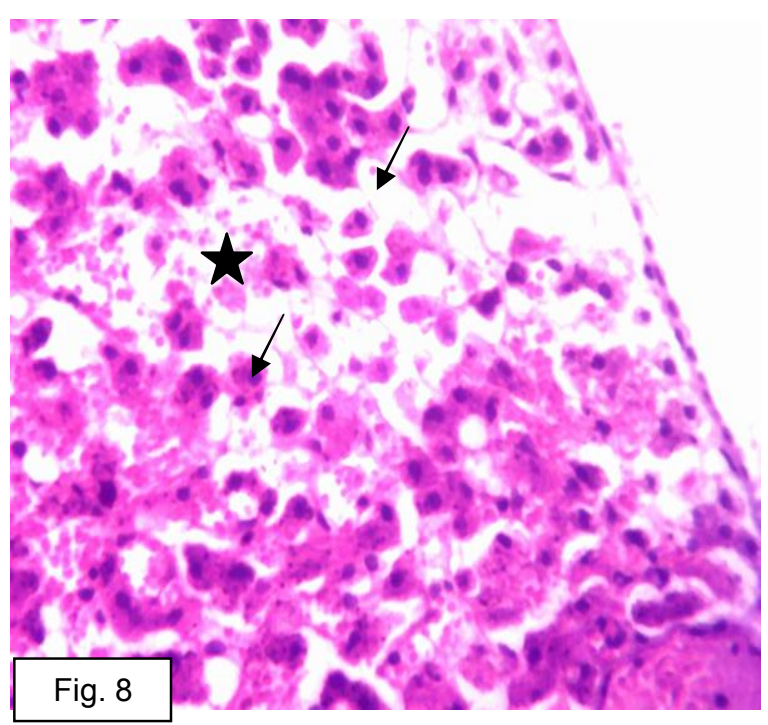

Fig. 8: Higher Magnification of Fig.7 showed hepatocellular Lysis (star), and pyknotic nuclei (arrow). X40.

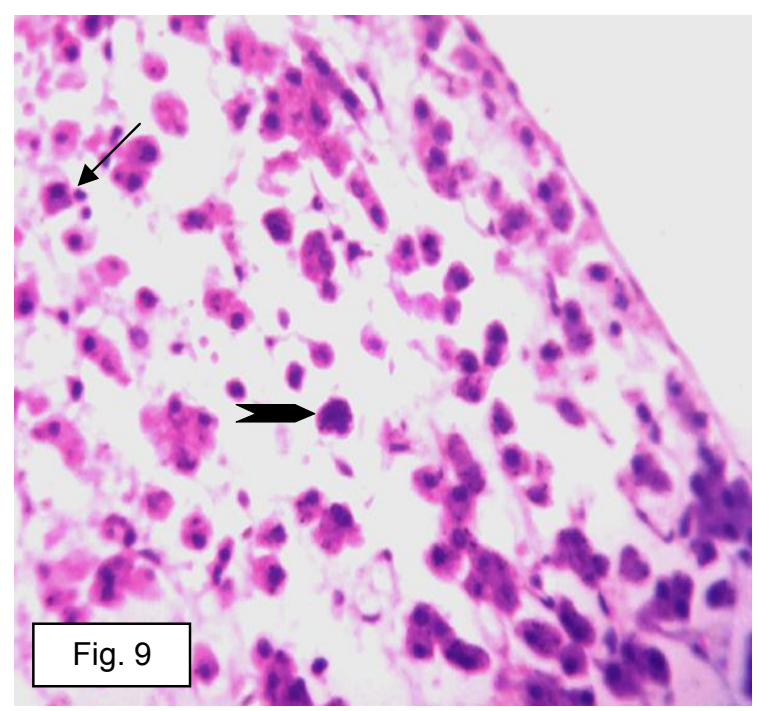

Fig. 9: Tiger liver showed hepatocellular lysis and nuclear Changes (pyknosis, Arrow; Karyorhexix, Head arrow). H.\&E.X40.

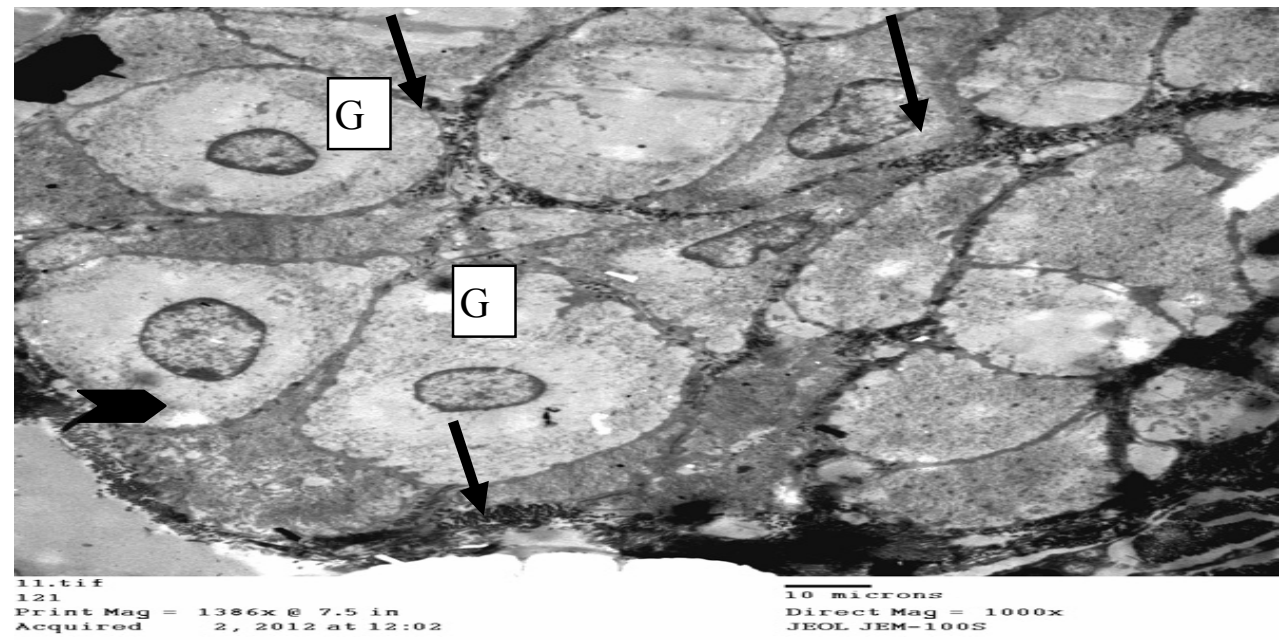

Fig.10: Electron-dense structures (arrow) in close contact with the gastric glandular epithelium (G). Bar=10um.

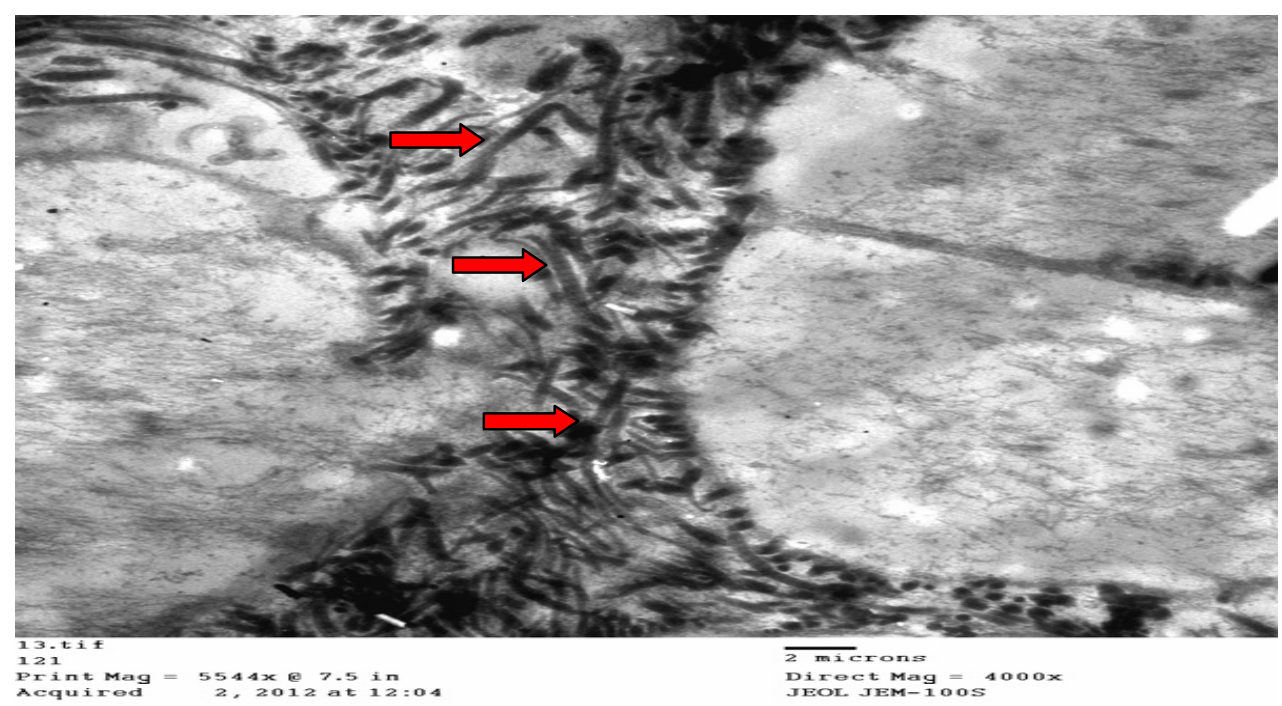

Fig.11: Higher magnification of Fig.10 showed elongated spiral-shaped bacteria (Helcobacteria sp,) (Arrow). Bar=2um 


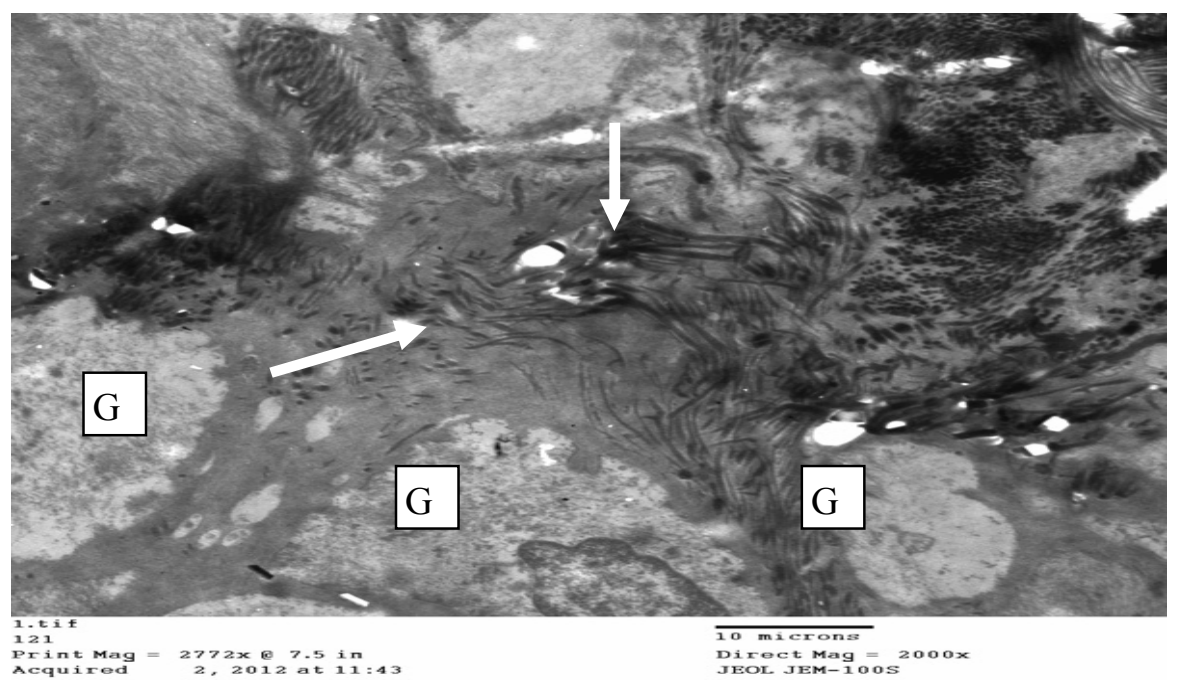

Fig. 12: TEM of tiger stomach showing spiral-shaped bacteria (arrow) between the gastric glandular Epithelium (G).bar=10um.

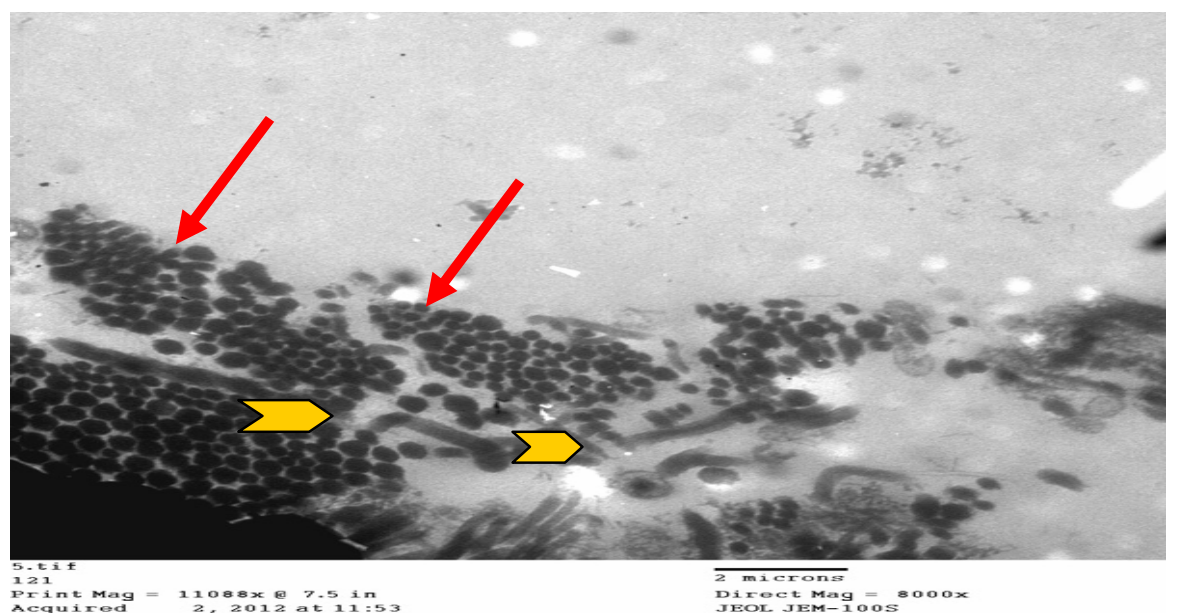

Fig.13: Higher Magnification of Fig. 12 showing spiral-shape bacteria (Head arrow) as well as rounded-shape (Arrow). Bar=2um.

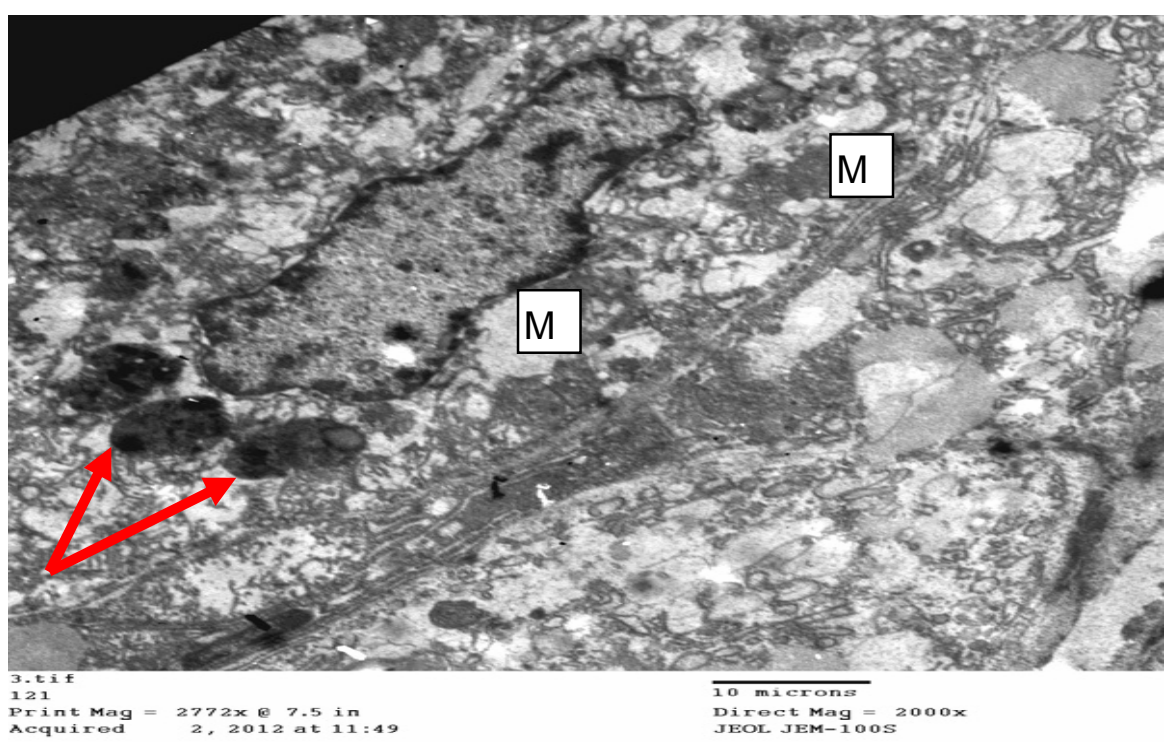

Fig.14: TEM of tiger stomach showing intracellular localization of bacteria (arrow) close to the mitochondria (M). Bar=10um. 
Assiut Vet. Med. J. Vol. 60 No. 140 January 2014

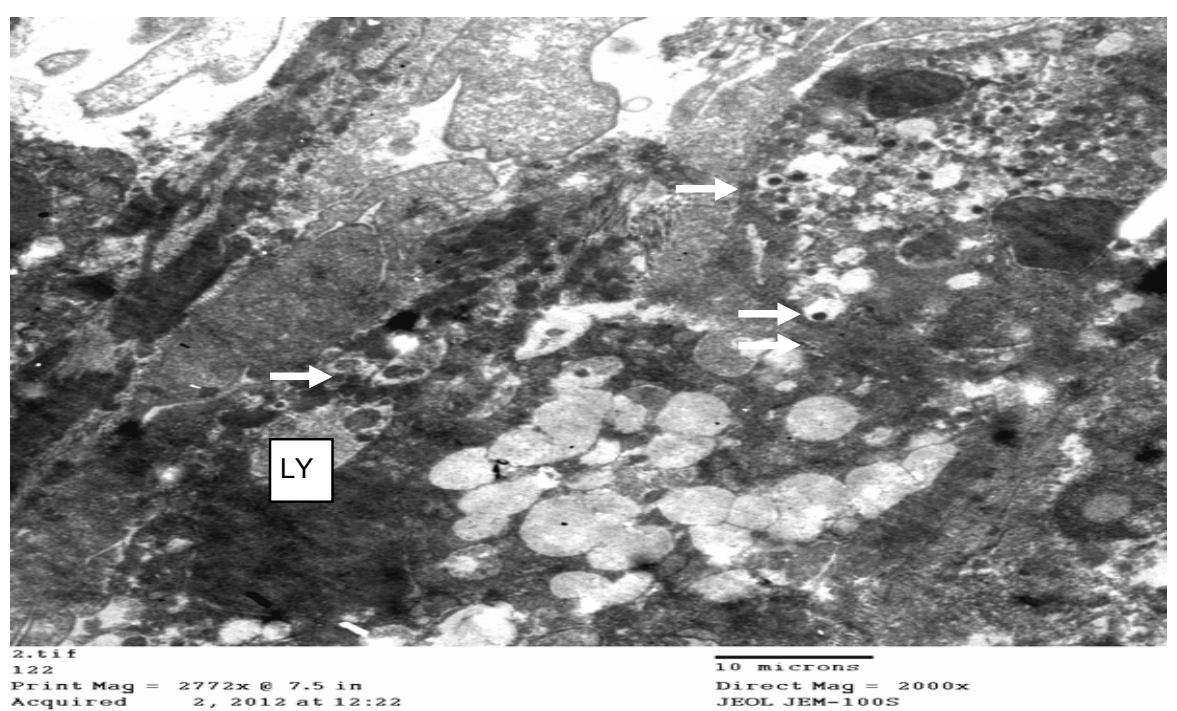

Fig.15: TEM of tiger doudenum showing intracellular localization of bacteria (arrow) surrounded by a hallow inside phagolysosomes (Ly). Bar=10um.

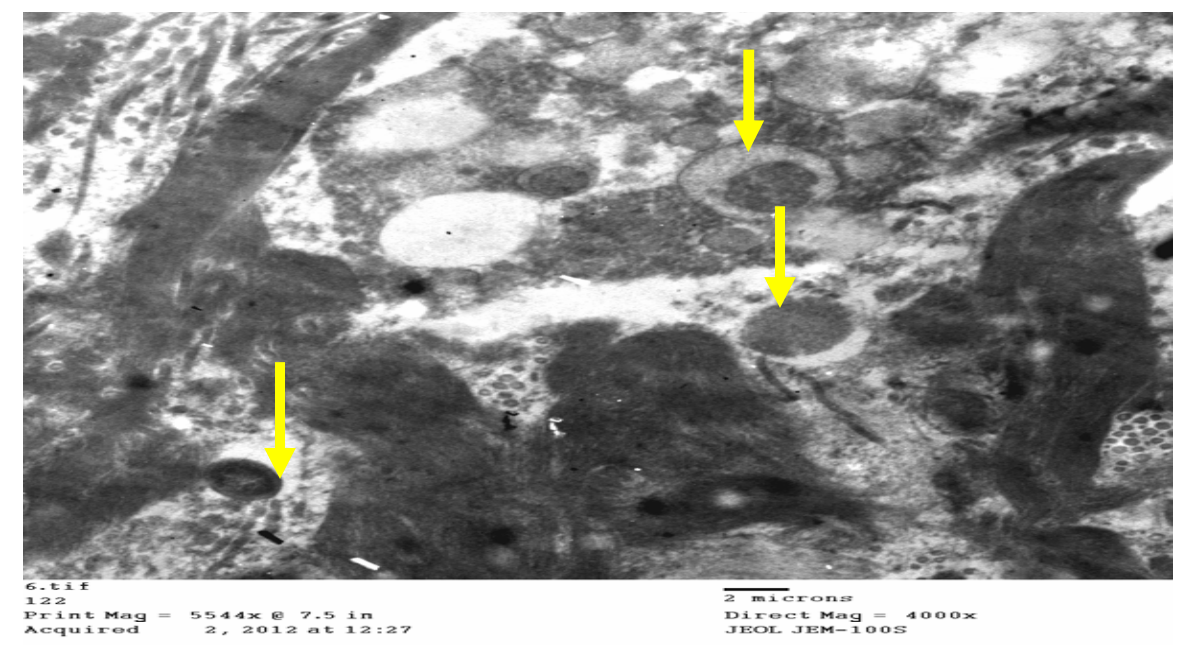

Fig.16: Higher magnification of Fig.15. Bar= 2 um.

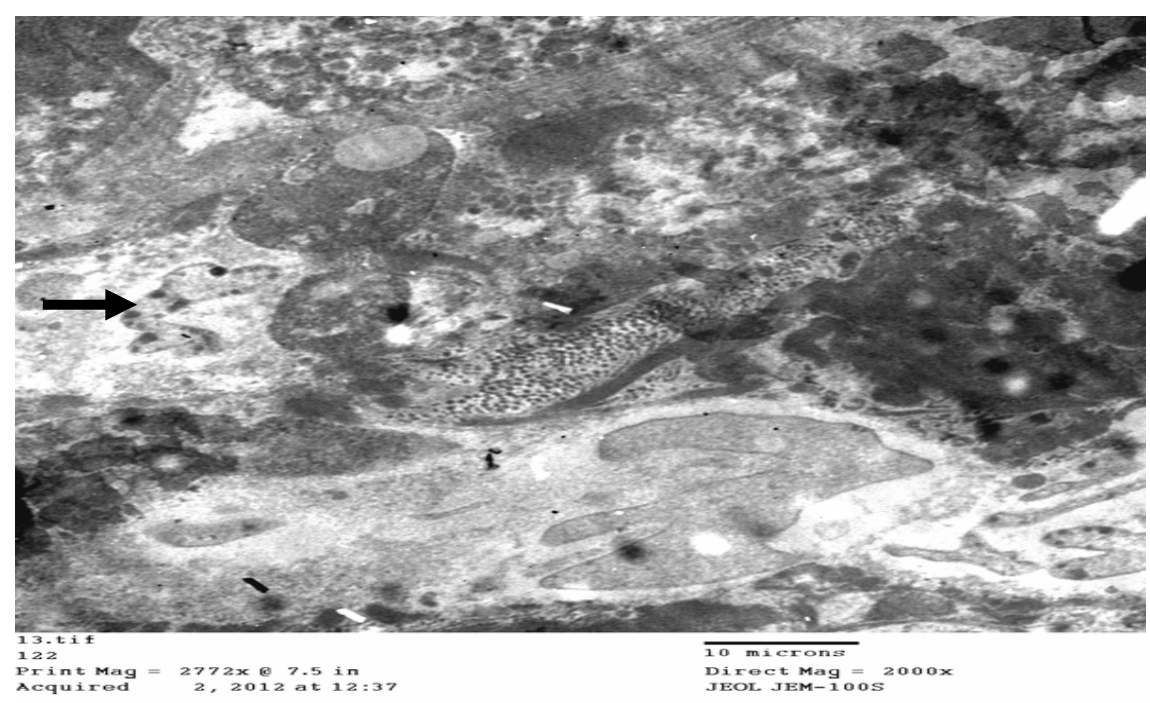

Fig.17: TEM of tiger doudenum showing intracellular localization of coiled spiral form of bacteria. Bar=10um. (arrow) 


\section{DISCUSSION}

In the present study post-mortum examination of the dead tiger revealed accumulation of straw in the inlet of the stomach. This condition in zoo animals is known as Phytobezoar.

(Barrs et al., 1999) recorded trichobezoars in five domestic crossbred cats (four long haired, one short haired. Phytobezoar recorded before in horses by (Banse et al., 2011 and MacDonald 1987). A juvenile male vervet monkey was found with a phytobezoar of straw obstructing the sigmoid colon also recorded in rhesus monkey (Macaca mulatta) (Kessler, and Kupper 1976).

Pronounced ulcers in the stomach was observed and surrounded with hemorrhagic zone.

Histopathological examination of tiger stomach in the present study showed different components of inflammation. Loss of mucosal surface epithelium and reached up to the superficial mucosal gastric glands was observed and explained the ulcer formation observed grossly. Moreover, necrosis of the gastric glands was evident. These changes represented the alterative component of inflammation. Hyperemia of the submucosal blood vessels was observed and suggested acute inflammation of the stomach occurred. Moreover, the vacuolated appearance of tunica intima endothelium may suggest alter membrane permeability. These changes together with the inflammatory cellular reaction suggest acutesubacute gastritis.

The present study showed subcapsular necrosis of the liver and manifested by hepaocellular lysis, as well as nuclear changes expressed by pyknosis and karyorehexis. Harbour and Sutton (2008) reported that Helicobacter hepaticus was originally isolated from the livers of mice suffering from multifocal necrotic hepatitis. It has since been found to colonize both the intestine and, less frequently, the liver of mice and is prevalent in many mouse colonies.

Transmission Electron Microscopy (TEM) in the present study showed the presence of elongated spiral coiled bacteria and suggested Helicobacter sp. Several studies have shown the features of these bacteria (Harbour and Sutton, 2008; Yamamoto et al., 2011). Moreover, the present study revealed that these bacteria were in close contact with the gastric glandular epithelium, intercellular and intracellular. These results suggest that Hellicobacter sp. is the main primary etiology responsible for the death of tiger due to acute gastritis. However, several rounded bacteria were also observed in association with the
Hellicobacter. These changes suggest that mixed infection occurred.

Schoroder et al. (1997) stated that Helicobacter. acinonyx from tigers, in which, as previously reported in cheetahs, it may be a cause of gastritis. Harbour and Sutton (2008) stated that in addition to infection of small domestic animals, there are numerous reports of Helicobacter-like organisms in a wide range of large cats and dogs, including lion, tiger, hyena, wolf, fox, bobcat, while these were not properly characterized. Yamamoto et al. (2011) stated that Helicobacter pylori (H. pylori), which is a gramnegative bacterium with a slightly curve-shaped morphology, colonizes the human stomach. Some non-H. pylori helicobacters (NHPH) found in the human stomach are sometimes observed in other animal species, such as cats, dogs, pigs, and primates. Therefore, human infections are suspected to be caused through human contact with these animals, and the possibility of the zoonotic transmission of animal Helicobacters to humans is a common concern. H. pylori is considered to be a major factor in the development of chronic atrophic gastritis, peptic ulcers, and gastric cancer (Yamamoto et al., 2011). Transmission electron microscopy revealed slightly curved organisms, 2-3um in length and 0. 0-5 um in diameter, in the gastric glands of the superficial mucosa. The bacteria were often found in close contact with the cell membrane of the gastric epithelial cells. In morphology and location, these organisms were similar to $H$. pylori of man and to $H$. acinonyx of cheetahs (Schoroder et al., 1997).

Although, reports indicated the absence of Helicobater bacteria in the duodenum (Schoroder et al., 1997; Harbour and Sutton, 2008). TEM in the present study showed the presence of coiled form and elongated bacteria as well as bacteria surrounded by hallow. Moreover, these bacteria were seen inside phagolysosomes.

In conclusion, the present study showed the dangerous of using the straw as bedding in the food rooms, Helicobacter bacteria observed as the primary etiology for gastritis in association with other rounded bacteria suggesting mixed infection occurred as a complication of the Phytobezoar and responsible for the death of tiger. Therefore, zoo keepers were recommended to avoid the use of straw as litter in the food rooms.

\section{REFERENCES}

Banse, HE.; Gilliam, LL.; House, AM.; McKenzie, HC.; Johnson, PJ.; Lopes, MA.; Carmichael, RJ.; Groover, ES.; Lacarrubba, AM.; Breshears, MA.; Brosnahan, MM.; Funk, R. and Holbrook, TC. (2011): Gastric and enteric 
phytobezoars caused by ingestion of persimmon in equids. J Am Vet. Med. Assoc. 2011; 239 (8): 1110-6.

Barrs, VR.; Beatty, JA.; Tisdall, PL.; Hunt, GB.; Gunew, M.; Nicoll, RG. and Malik, R. (1999): Intestinal obstruction by trichobezoars in five cats . J Feline Med Surg. Dec; 1(4): 199-207.

Chisholm, E.M.; Leong, H.T.; Chung, S.C. and Li, A.K. (1992): "Phytobezoar: An uncommon cause of small bowel obstruction". Annals of the Royal College of Surgeons of England 74 (5): 342-344.

Harbour, S. and Sutton, P. (2008): Immunogenicity and pathogenicity of Helicobacter infections of veterinary animals. Veterinary Immunology and Immunopathology 122: 191-203.

Schröder1, H.-D.; Ludwig, C.; Jakob1, W.; Reischl, U.; Stolte1, M. and Lehn, N. (1998): Chronic gastritis in tigers associated with Helicobacter acinonyx. Journal of Comparative Pathology Volume 119, Issue 1, 67-73.

Kessler, MJ. and Kupper, JL. (1976): Obstructive gastric foreign body in a rhesus monkey (Macaca mulatta). Lab Anim Sci.; 26(4): 619-21.

Lagios, MD. and Suydam, MJ. (1968): Emphysematous gastritis with perforation complicating phytobezoar. Am. J. Dis. Child. Aug; 116(2): 202-4.

MacDonald, M H.; Richardson, Dean, W. and Morse, C.C. (1987): Esophageal phytobezoar in a horse. Journal of the American Veterinary Medical Association. (9): 11:1455-1456.

Murakami, T.; Vamamoto, K.; Itoshima, T. and Irino, S. (1977): Modified tannin-osmium conductive staining method for non-coated scanning electron microscope specimens. Its application to microdissection scanning electron microscopy of the spleen. Archivum histologicum Japonicum $=$ Nihon soshikigaku kiroku.; 40 (1): 35-40.

Schroder, H.D.; Ludwig, G.; Jakob, W.; Reischl, U.; Stolte, M. and Lehn, N. (1997): Chronic Gastritis in Tigers Associated with Helicobacter acinonyx. J. Comp. Pathology, 119, 67-73.

Yamamoto, K.; Tanaka, H. and Nishitani, Y. (2011): Helicobacter suis KB1 derived from pig gastric lymphoid follicles induces the formation of gastric lymphoid follicles in mice through the activation of B cells and CD4 positive cells. Microbes Infect 13: 697-708.

\title{
استخدام الميكروسكوب الضوئي والاكتروني القاطع لدراسة التغيرات المصاحبة لالتهاب المعدة لاى النمور البنغالي
}

\author{
عمر تمام \\ E-mail: Otamam2002@hotmail.com
}

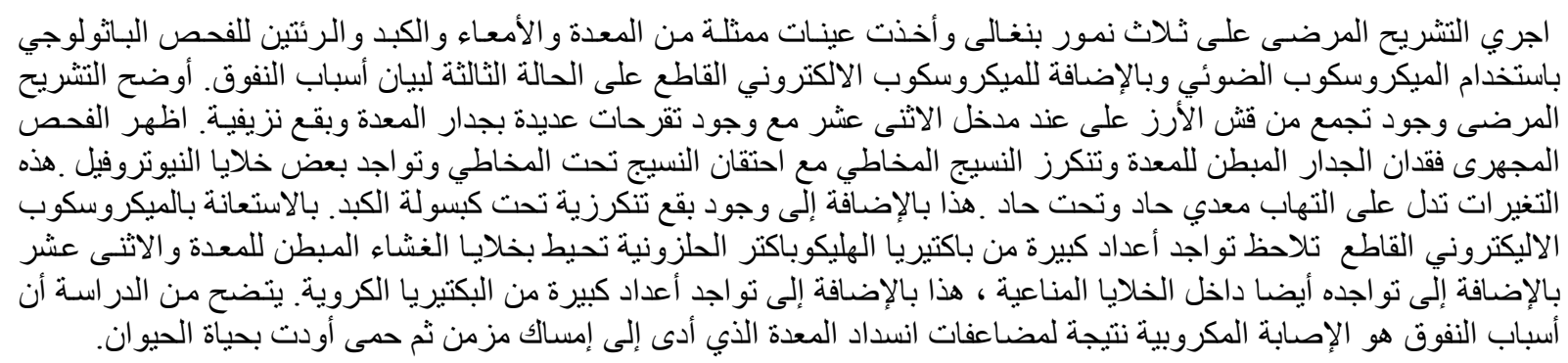

